\title{
CHANGES IN POSTURAL STEADINESS FOLLOWING TRANS-TIBIAL AMPUTATIONS
}

Douglas Henness, Arianna Medema, Kendra Steinhorst, Robert Moauro, Michael Reuland, Robert Whelan, Shawna Kester, Hamid Bateni*

Physical Therapy Program, Northern Illinois University, DeKalb, IL, USA.

*Email: hbateni@niu.edu

DOI: https://doi.org/10.33137/cpoj.v1i2.32014

\section{INTRODUCTION}

Increased risk of falling following amputation is well documented in literature ${ }^{1}$. As the amputee population ages, accidental falls become a greater problem. Transtibial amputations are one of the most common levels of amputation. We hypothesized that postural steadiness is deteriorated following trans-tibial amputation as compared to age matched younger adults.

\section{METHODS}

Data from three trans-tibial amputees $(51 \pm 16$ years old) and six healthy age matched ( $48 \pm 19$ year old) were analyzed. Participants were instructed to stand (bare feet - heels together, 5-7 degrees toe-out) on a force platform and were tested for three standing conditions: a- eyes open, b- eyes closed and c- standing on Airex 2.5" thick balance pad (www.airex.com). Each test was repeated three times (block randomized). Force platform data were collected for 35 seconds. Anteroposterior and mediolateral time series data were filtered through a fourth-order zero phase Butterworth low-pass filter with cut-off frequency of $5 \mathrm{~Hz}$. The first $8 \mathrm{sec}$. and last $2 \mathrm{sec}$. of data were cut off to remove any potential lead-in/out effect.

\section{RESULTS}

Analysis of variance on time and frequency domain variables of sway indicated significant differences among amputees vs. non-amputees. Mean mediolateral sway distance and the standing conditions were significantly different $(\mathrm{F}(1,5)=5.83, \quad \mathrm{p}<0.05$ and $\mathrm{F}(1,5)=3.84, \mathrm{p}<0.05$ respectively). The maximum $\mathrm{ml}$ sway velocity was also affected by amputation $(\mathrm{F}(1,5)=17.66, \quad \mathrm{p}<0.0001)$. In frequency domain variables, Power in $\mathrm{ml}$ direction was both affected by amputation $(\mathrm{F}(1,5)=10.66, \mathrm{p}<0.001)$ and test condition $(\mathrm{F}(1,5)=4.16, \mathrm{p}=0.019) .95 \%$ AP power frequency and centroidal frequency were also affected by amputation $(\mathrm{p}=0.013$ and 0.003 respectively).

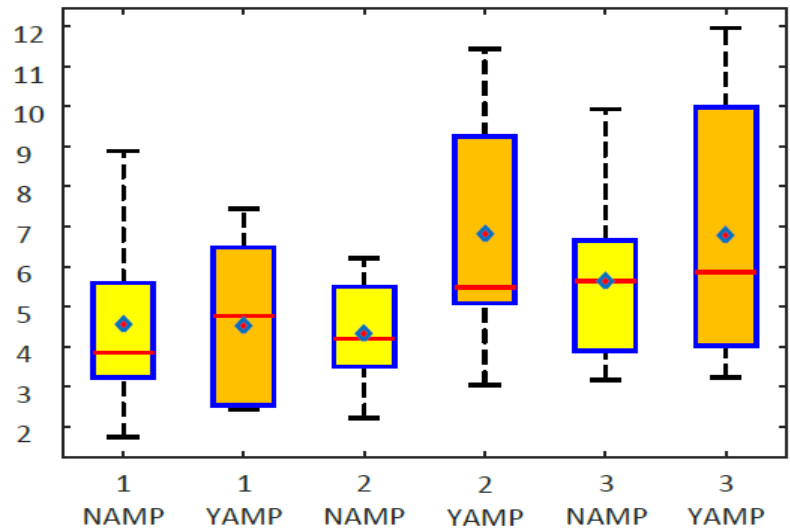

Figure 1. comparison of ML postural sway of amputees (YAMP) and non-amputees (NAMP) for three standing conditions of 1 (eyes open), 2(eyes closed) and 3 (standing on foam). Horizontal cross line indicated median and diamond shape indicates mean value of the data.

\section{CONCLUSION}

Our results indicate that postural steadiness is altered following amputation both in time and frequency domain.

\section{SIGNIFICANCE}

Assessment of postural steadiness in both time and frequency domain can reveal a new aspect in assessment of balance and postural control among amputees and can lead to more effective training exercises as well as optimizing prosthetic component designs to reduce accidental fall among this population.

\section{REFERENCES}

1- C. Gauthier-Gagnon, M. C. Grise, and D. Potvin, Enabling factors related to prosthetic use by people with transtibial and transfemoral amputation. Arch. Phys. Med. Rehabil. 1999; vol. 80, pp. 706-713.

\section{DISCLOSURE}

No conflict of interest exists for this study. 